Journal of the Rubber Research Institute of Sri Lanka, (2007) 88, 1-21

\title{
Adoption of different tapping systems in the rubber industry of Sri Lanka with special reference to low frequency tapping
}

\author{
V H L Rodrigo*
}

Received 24 July 2006; Accepted 01 January 2007

\begin{abstract}
Tapping is the most costly activity in natural rubber production and the shortage of tappers is a serious problem in rubber plantations in Sri Lanka. Low Frequency Tapping (LFT) systems are considered to be a solution to these issues by reducing the number of tappers required and increasing tappers' income. With no information available on the adoption of different tapping systems, the present study was aimed to assess the existing tapping systems and associated effects on the productivity and other related issues in both plantation and smallholder sectors in Sri Lanka. Also, focus was given to identify the factors hindering for the adoption of LFT. Information was initially gathered using questionnaire based surveys and then verified through participatory workshops. The study revealed that the poor productivity in the plantation sector was highly associated with the shortage of skilled tappers. Productivity of the smallholdings tapped with family labour was less than that of smallholdings tapped with hired labour and this had been associated with the quality of tapping. In general, incorrect agromanagement practices have resulted in poor productivity. With no proper knowledge, the adoption of the LFT was rather poor in the plantation sector and zero in the smallholder sector.

In view of addressing the issues related to the tapper shortage, an effective programme was proposed with the application of LFT. It comprised with improved crop management practices and proper incentive schemes that transmit some benefits of LFT to tapper. Tapper training programmes and large scale demonstrations with model cluster systems were identified as primary needs for the effective introduction of LFT.
\end{abstract}

Key words: low frequency tapping, plantations, rubber, smallholders, tapping systems

\section{Introduction}

Exploitation of latex (tapping) is the most costly operation in the rubber crop and in the plantation sector, it contributes to $c a .1 / 3$ of the cost of production. In addition, it requires greater level of skill and this is partly associated with the problem of skilled

* Rubber Research Institute of Sri Lanka, Dartonfield, Agalawatta, Sri Lanka 
Tapping systems in Sri Lanka

tapper shortage. This problem is aggravated under poor market prices of rubber when any increase in tappers' wages cannot be afforded and also under unfavourable weather conditions offering interrupted working days. Ultimate effect is such that large extents of productive rubber clearings have been left without tapping. It had been apparent that over $20 \%$ of vacant tapping blocks existed in the plantation sector due to the shortage of tappers (Nugawela et al., 2000), whilst over 3500 hectares had been left untapped in smallholder sector due to the same or its combined effect with poor market prices of rubber during the latter part of 90's (unpublished data of Advisory Services Department of RRISL). Further, to overcome this issue, unskilled tappers are also being employed lowering the long-term yield potential of rubber trees. Removal of skill factor has not been successful and not cost effective in instances where it has been tried (eg. Mechanized tapping), hence local and international focus has been made to introduce low frequency tapping systems (LFT) keeping down the requirement of tappers to a bear minimum.

In LFT, time gap between two tappings is extended by few more days, therefore each tapper can be allocated to a greater number of trees resulting in reduced tapper requirement when compared with the traditional tapping system. In order to compensate the yield loss due to less number of tapping days per tree, yield stimulants are applied thereby yield per tree per tapping increases. This results in enhanced daily intake per tapper and therefore, tappers' wages can be increased. Furthermore, overall increase in tappers' productivity results in reduction of cost of production. With less number of tapping days per year, economic life of the tree increases providing an additional benefit to the growers.

In Sri Lanka and elsewhere, rubber trees are generally tapped on alternate days $(d / 2)$. Experiments in India were in favour of LFT systems (Vijayakumar et al., 2000; Karunaichamy et al., 2001) with that tapping a tree once in four days and six days is recommended (Vijayakumar et al., 2005). LFT systems of $\mathrm{d} / 3$ and $\mathrm{d} / 5$, (i.e. tapping a tree once in 3 to 5 days) are practiced in China (Wei Xiaodi et al., 2005). Response of different genotypes (rubber clones) to LFT systems differs (Vijayakumar et al., 2005) and would depend on the climatic conditions. Experiments on LFT systems in Sri Lanka were basically on $\mathrm{d} / 3$ systems, i.e. tapping once in three days with stimulation $(d / 3+E T)$. First recommendation on this system was issued in 1994 (Anon, 1994) and this would bring down the tapper requirement by $1 / 3$ and cost of tapping by ca. 20\% (Nugawela et al., 2000). However, little information, if any, is available on the adoptability of the system indicating that this may be limited to few holdings. Therefore, the objective of the present study was to assess the existing tapping 


\section{H L Rodrigo}

systems/policies and related issues in both plantation and smallholder sectors and thereby to identify the hindering factors for the Low Frequency Tapping (LFT). Also, it was aimed at identifying suitable tapping systems for different categories of smallholders through characterizing their needs.

\section{Materials and Methods}

The study was conducted in 2003/4 covering both plantation and smallholder sectors of major rubber growing areas of the country, i.e. Kalutara, Kegalle and Rathnapura districts of low country wet zone.

In the assessment of a social system, questionnaire based rapid appraisals/surveys are powerful tools in terms of quantification of required or known characteristics. However, those may not be suitable in finding out the hidden facts and possible implications in technology adoption in a complex system. Therefore in each sector, the study comprised two phases; first a questionnaire based rapid appraisal and then participatory workshops to verify the outcomes of the rapid appraisals.

\section{Plantation sector}

\section{Rapid appraisal}

A questionnaire for the rapid appraisal was formulated using the checklist given in Table 1 and aimed at investigating the issues related to tapper shortage in the plantation sector of the rubber industry. The questionnaire was pre-tested in two commercial plantations and then, sent by post to 160 estates in 17 Plantation Companies that governed all rubber plantations in Sri Lanka. Information was provided by 69 estates representing all 17 companies. Random checking was carried out to validate the information provided by the estates. However, data analyses were confined to 55 estates in 11 companies due to discrepancies in the information provided.

Yield performance of each estate with respect to land area and tapper productivity was assessed. Tapper availability was evaluated in terms of average daily outturn of both permanent and substitute tappers and vacant tapping blocks. Adoption of the LFT and its potential effectiveness to solve the negative effects of tapper shortage were assessed. The age distribution of tappers was also examined in order to assess the future trends in tapper availability. Also, availability of casual labour was examined to explore the possibilities of training them for tapping.

Data analyses were conducted mainly on rather descriptive manner. In order to derive the parameters at national level, data were initially summarised on estate basis and then overall figures derived. However, data were analysed, where necessary, on company basis, i.e. only for the companies of which more than three estates provided information requested by the questionnaire.

\section{Workshop for planters}

After the data analyses, a 
Tapping systems in Sri Lanka

central workshop (one day) was organised at the RRISL for the planters in order to review the outcome of the rapid appraisal and then to decide the measures to be taken up to overcome the problems associated with tapper shortage. Managers of rubber plantations who responded to the questionnaire-based survey were the invitees of the workshop and in total 42 planters participated. Work programmes of some plantation companies did not permit all invitees to participate in the workshop, but allowed reasonable representation. In addition to the planters, scientists and technicians working on rubber exploitation joined the workshop.

Based on the findings of the rapid appraisal, an overall review on the productivity and tapper related issues in the plantation sector was presented together with an analysis on the effectiveness of LFT to address the tapper shortage. Then the planters were divided into four groups during the working session in which each group discussed the key issues of the review presented, the practicality of LFT and any other measures to be taken up to address the tapper shortage.

Each group comprised with planters from different companies and areas and scientists acted purely as facilitators in the discussion process. At the end of the discussion, each group presented their decisions. On issues where groups were in different opinions, there was an extended discussion to scrutinise decisions/conclusions.

\section{Smallholder sector}

\section{Rapid appraisal}

Preliminary level information on rubber tapping in the smallholder sector was gathered through discussions with extension personnel. Three categories of labour use in tapping, i.e. tapping with family, hired and both types of labour, were identified. This was followed by a questionnaire based survey in three major rubber growing areas of the country (i.e. Kalutara, Kegalle and Rathnapura) with the focus on assessing the tapping systems associated with above categories. The questionnaire was formulated using the checklist given in Table 1 and pre-tested with five smallholders. Tapping quality was assessed with field observation on randomly selected 25 trees. The percentage trees with correct adoption of five quality parameters, i.e. tapping angle, depth and cut length, bark consumption and proper use of tapping utensils, was counted and the mean value was obtained as the percentage value of tapping quality.

Smallholders for the survey were selected based on a stratified sampling procedure and on-site farmer interviews were conducted. Each rubber growing region comprised with several ranges, each with a Rubber Development Officer (RDO), as Kalutara 38, Kegalle 61 and Rathnapura 30. However, due to the practical reasons, only 10 ranges were selected from each region for the survey. Increased distance of travel limited the number of ranges used for the survey in 
V H L Rodrigo

Table 1. Checklists used in the questionnaire based rapid appraisals in both plantation and smallholder sectors

\begin{tabular}{|c|c|}
\hline Plantation Sector & Smallholder Sector \\
\hline $\begin{array}{l}\text { - Productivity levels and tapping systems } \\
\text { - Availability and the requirement of tappers } \\
\text { in different plantations } \\
\text { - Availability of skill tappers } \\
\text { - Financial loss due to tapper shortage } \\
\text { - Extent to which a low frequency tapping } \\
\text { system is practised. } \\
\text { - Potential area for the d/3 system and how it } \\
\text { will solve the tapper shortage } \\
\text { - Distribution of tappers in different age } \\
\text { categories } \\
\text { - Availability and the requirement of casual } \\
\text { labourers in different plantations } \\
\text { - Casual labourers falling into different age } \\
\text { categories }\end{array}$ & $\begin{array}{l}\text { - Social and educational status of the } \\
\text { smallholder } \\
\text { - Age of the rubber crop } \\
\text { - Type of labour use and labour } \\
\text { availability } \\
\text { - Agronomic practices in rubber } \\
\text { cultivation } \\
\text { - Tapping systems adopted and } \\
\text { knowledge on low frequency tapping } \\
\text { - Quality of tapping } \\
\text { - Way of processing and marketing } \\
\text { - Social networks }\end{array}$ \\
\hline
\end{tabular}

the Kegalle region to 7 . In order to obtain a good representation of the region, adjacent ranges were avoided in the selection process. In each range, three smallholdings from each type of labour use category were intended to sample, however tapping with both family and hired labour was practised only in few smallholdings, limiting its total sample size to 12 smallholdings. In total, 73 and 74 smallholdings were surveyed from other two labour use categories, i.e. tapping with only family and hired labour, respectively.

Since data collection was done on the basis of labour use types in tapping, data were summarised on the same basis. With few smallholders found to be tapped with both family and hired labour, this smallholder category was not taken into the most of data analyses. Smallholders had different types of occupations and for the convenience in data analyses, those occupations were categorized into four groups, e1) who were disabled to do any job, e2) who were engaged in laborious jobs, e.g. tappers and labourers, e3) who engaged in low income level jobs, but on permanent basis, e.g. drivers, minor staff workers and low level business and e4) who engaged in respectable jobs in the society, e.g. teachers, Gramaseveka, bank and labour officers, accountants and above moderate business. Social status maintained by smallholders was ranked into three where "High" refers to people who were having a four wheel vehicle, telephone and electricity, and "Low" for those who did not have any of above items whilst people in "Moderate" category fell in between "High" and "Low". Income levels of the people could not be assessed directly 


\section{Tapping systems in Sri Lanka}

hence following criteria were used. People in the occupational category el or e2 with a land below 1 ac were categorised into the income level below Rs.5,000/=, whilst those having a medium grade job with a land up to 2 ac were supposed to be in the income category Rs.5,000-10,000/=. If a person had a medium grade job (including business) with a land over $2 \mathrm{ac}$, he was taken into the category of Rs.10,000$20,000 /=$. People who were having staff grade job or large scale business and/or four wheel vehicle and/or land over 6 ac, were supposed to be in the income category above Rs.20,000/=.

\section{Workshop for smallholders}

After the data analyses, regional workshops were conducted in selected villages (one per each region). Problems associated with transport facilities did not allow gathering all smallholders in the region to these workshops; however farmers in adjacent villages participated in the workshop. Based on the findings of the rapid appraisal, an overview of the productivity and tapper related issues in the smallholder sector was presented giving attention in particular to the all regions and to the region where the workshop was held. Then according to the type of labour use in tapping, the participants were grouped for the working session in which each group discussed the key issues of the review presented, the practicality of LFT and any other measures to be taken up to address the tapper shortage. Also, discussions were made on an action plan to overcome the problem of tapper shortage. Although attempts were made to group the participants on gender basis, there was no sufficient number from females to do so, resulting in mixed participation in each group. During the discussions, researchers were purely facilitators and the views of each group were recorded.

\section{Results}

\section{Plantation sector}

Outcome of the rapid appraisal

The productivity of latex production at the estate level varied between 530 tol314 $\mathrm{kg} \mathrm{ha}^{-1}$ on area basis and from 3 to $9.8 \mathrm{~kg} \mathrm{day}^{-1}$ on tapper basis with mean values of 893 and $6.4 \mathrm{~kg}$, respectively (Table 2). Number of trees allocated to each tapper was 600 and in general, in a two tapping blocks. All estates practised d/2 tapping system (i.e. tapping a tree on every other day) and in $87 \%$ of their mature rubber. Low frequency tapping with ethephon stimulation was practised by a few estates (10\%) and in an area representing less than $2 \%$ of total mature extent of the plantation sector. However, the LFT was generally practised without stimulation in a larger extent ( $c a .10 \%)$ during the first year of tapping (i.e. $48 \%$ estates) and for the clones recommended for tapping at $\mathrm{d} / 3$ without stimulation (i.e. $25 \%$ estates) (Table 2).

On an average for the plantation sector, trees with intensified tapping occupied in the $13.5 \%$ of mature extent whilst the composition of the area under 


\section{H L Rodrigo}

the $d / 2$ tapping in virgin and renewed barks were $55 \%$ and $32 \%$, respectively (Table 2). The daily total requirement of tappers in an estate depended on the area under mature rubber, however on average, tapper requirement of an estate was 135 (Table 3). More importantly, hardly any company or estate had permanent tappers up to the requirements. On average for an estate, availability of permanent tappers has been limited to $71 \%$ whilst usage of substitute tappers was $17 \%$ of the total tapper requirement. Therefore, untapped area represented by the vacant tapping blocks, occupied $12 \%$ of the mature extent.

Table 2. Productivity levels and the adoption of tapping systems in the plantation sector of the rubber industry of Sri Lanka. Technical terms $1 / 2 S d / 2$ and $1 / 2 S d / 3$ refer to half spiral tapping at every two and three days frequencies, respectively whilst ET is for ethephon stimulation (Rodrigo et al., 2004).

\begin{tabular}{|c|c|}
\hline Average yield $(\mathrm{kg} / \mathrm{ha} / \mathrm{yr})$ & 893.4 \\
\hline Average daily intake per tapper $(\mathrm{kg})$ & 6.4 \\
\hline Proportion of estates practising $1 / 2 \mathrm{~S} \mathrm{~d} / 2$ tapping & $100 \%$ \\
\hline Proportion of estates practising $1 / 2 \mathrm{~S} d / 3+\mathrm{ET}$ & $10 \%$ \\
\hline Proportion of estates practising $1 / 2 \mathrm{~S} d / 3$ during the $1^{\text {st }}$ year of tapping & $47.8 \%$ \\
\hline Proportion of estates practising $1 / 2 S d / 3$ for $d / 3$ clones & $24.6 \%$ \\
\hline Proportional extent under $1 / 2 \mathrm{~S} d / 2$ tapping; total & $87.6 \%$ \\
\hline in virgin bark & $54.8 \%$ \\
\hline in renewed bark & $31.8 \%$ \\
\hline Proportional extent under intensified tapping & 13.5 \\
\hline Proportional extent under $1 / 2 \mathrm{~S} \mathrm{~d} / 3+$ ET tapping & 1.3 \\
\hline Proportional extent under $1 / 2 \mathrm{~S} d / 3$ during the $1^{\text {st }}$ year of tapping & 5.4 \\
\hline Proportional extent rubber under $1 / 2 \mathrm{~S} d / 3$ for $\mathrm{d} / 3$ clones & 5.6 \\
\hline
\end{tabular}

On an average, potential yield loss due to vacant blocks was as high as $118 \mathrm{~kg} \mathrm{ha}^{-1}$ per year (Table 3). However, in some plantation companies, this value was extremely high with the highest value recorded as $278 \mathrm{~kg} \mathrm{ha}^{-1}$ year ${ }^{-1}$. The majority of tappers ( $c a$. $60 \%$ ) were in the age group of 31 to 50 (Fig.1). Tappers falling into the age groups of 21-30 and 51-60 were more or less same and only a few were in the age above 60 and below 20. Similar to the age distribution of tappers, number of casual labourers falling into the age group 31 to 50 was the greatest, followed by 21-30yr and 51-60yr age categories (Fig. 1). 
Tapping systems in Sri Lanka

Table 3. Summary on the tapper requirement and availability in plantation companies of Sit Lanka. Only the companies of which more than three estates responded to the questionnaire are shown. Values represent the mean for the estates in different plantation companies with standard error (Rodrigo et al., 2004).

\begin{tabular}{|c|c|c|c|c|c|}
\hline \multirow[b]{2}{*}{ Company } & \multirow{2}{*}{$\begin{array}{l}\text { Tapper } \\
\text { requirement } \\
\text { per day }\end{array}$} & \multicolumn{3}{|c|}{$\begin{array}{c}\text { Usage of tappers \& vacant tapping } \\
\text { blocks }\end{array}$} & \multirow{2}{*}{$\begin{array}{l}\text { Yield loss due to } \\
\text { vacant tapping } \\
\text { blocks (kg/ha/yr) }\end{array}$} \\
\hline & & $\begin{array}{l}\text { Permanent } \\
\text { tappers \% }\end{array}$ & $\begin{array}{l}\text { Substitute } \\
\text { Tappers \% }\end{array}$ & $\begin{array}{c}\text { Vacant } \\
\text { blocks \% }\end{array}$ & \\
\hline A & $154( \pm 18)$ & $77.2( \pm 8.1)$ & $10.9( \pm 6.6)$ & $11.9( \pm 6.1)$ & $112.7( \pm 15.1)$ \\
\hline$B$ & $228( \pm 44)$ & $93.1( \pm 3.8)$ & $5.9( \pm 5.0)$ & $1.0( \pm 0.6)$ & $97.1( \pm 6.3)$ \\
\hline $\mathrm{C}$ & $62( \pm 18)$ & $69.6( \pm 4.1)$ & $5.1( \pm 4.6)$ & $25.3( \pm 4.7)$ & $223.5( \pm 40.2)$ \\
\hline $\mathrm{D}$ & $106( \pm 40)$ & $74.5( \pm 4.6)$ & $13.9( \pm 5.3)$ & $11.9( \pm 5.3)$ & $101.1( \pm 24.1)$ \\
\hline $\mathrm{E}$ & $99( \pm 41)$ & $48.0( \pm 8.1)$ & $21.4( \pm 3.6)$ & $30.6( \pm 4.5)$ & $278.1( \pm 5.5)$ \\
\hline$F$ & $225( \pm 42)$ & $21.5( \pm 4.6)$ & $76.8( \pm 4.3)$ & $1.7( \pm 1.8)$ & $12.6( \pm 3.1)$ \\
\hline $\mathrm{G}$ & $153( \pm 29)$ & $90.8( \pm 5.2)$ & $3.2( \pm 3.4)$ & $6.0( \pm 2.3)$ & $55.7( \pm 44.6)$ \\
\hline $\mathrm{H}$ & $89( \pm 32)$ & $70.3( \pm 4.0)$ & $7.9( \pm 3.3)$ & $14.5( \pm 3.9)$ & $149.5( \pm 13.2)$ \\
\hline I & $103( \pm 23)$ & $92.8( \pm 2.5)$ & $3.8( \pm 3.1)$ & $3.7( \pm 0.7)$ & $31.7( \pm 15.4)$ \\
\hline
\end{tabular}

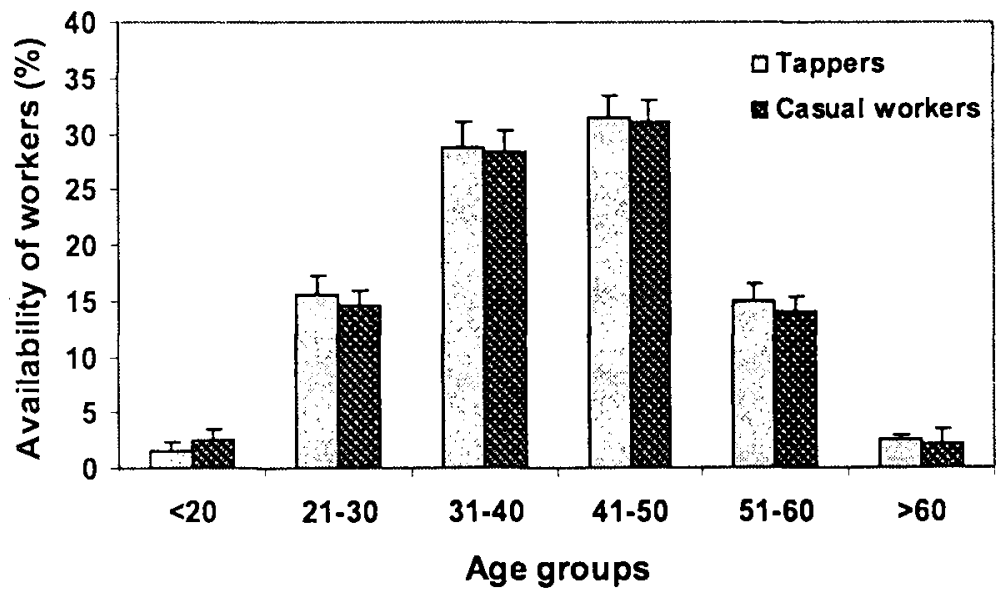

Fig. 1. Age distribution of tappers and casual workers in plantations. Values represent the mean for 55 estates with standard error as error bars

The composition of skill tappers was only $62 \%$ leaving $38 \%$ as unskilled (Table 4). In some estates, percentage of unskill tappers was as high as $89 \%$. Gender ratio of tappers was biased towards female representing over $60 \%$. However, in the case casual workers, females were only $53 \%$ showing $c a$. $10 \%$ difference from tappers. 


\section{H L Rodrigo}

Table 4. Status of tappers and casual labourers on basis of gender and skill for tapping in plantation companies of Sri Lanka. Only the companies of which more than three estates responded to the questionnaire are shown. However, the mean value represents all estates (55) responded to the questionnaire (Rodrigo et al., 2004).

\begin{tabular}{ccccccc}
\hline & \multicolumn{3}{c}{ Tappers } & \multicolumn{2}{c}{ Casual workers } \\
\cline { 2 - 7 } Company & \% Male & \% Female & \% Skilled & \% Unskilled & \% Male & \% Female \\
\hline A & 29.77 & 70.23 & 63.9 & 36.1 & 51.3 & 48.7 \\
B & 56.05 & 43.95 & 74.1 & 25.9 & 49.2 & 50.8 \\
C & 42.87 & 57.13 & 73.35 & 26.65 & 41.97 & 58.03 \\
D & 18.1 & 81.9 & 33.24 & 66.76 & 54.88 & 45.12 \\
E & 25.96 & 74.04 & 61.19 & 38.81 & 54.1 & 45.9 \\
F & 69.86 & 30.14 & 69.47 & 30.53 & 31.32 & 68.68 \\
G & 35.13 & 64.87 & 75.53 & 24.47 & 42.33 & 57.67 \\
H & 29.84 & 70.16 & 40.8 & 59.2 & 41.08 & 58.92 \\
I & 26.28 & 73.72 & 97.54 & 2.46 & 43.23 & 56.77 \\
Mean & 37.17 & 62.83 & 62.18 & 37.82 & 46.61 & 53.39 \\
\hline
\end{tabular}

Outcome of the workshop

All participants agreed with the information surfaced from the rapid appraisal and emphasised that the problem of tapper shortage in the rubber industry should be addressed without any delay. The general opinion was that the tapper shortage is governed by poor social dignity for tappers, unfavourable weather conditions resulting in interrupted working days, poor wage structure for tappers with lack of incentives, poor ground conditions (eg. weeds) and infrastructure facilities (eg. long distance head carrying of latex) and lack of tapper training programmes.

Most of participants were not aware of the full protocol of the LFT. However the workshop was an opportunity for them to discuss all aspects of the LFT. Participants preferred to practise LFT with stimulation $(1 / 2 S d / 3+E T)$ on trail basis instead of the most widely adopted alternate day tapping, i.e. $1 / 2 \mathrm{~S} \mathrm{~d} / 2$ due to the reduced requirement of tapper. As LFT alone cannot solve the problem of tapper shortage in long run, participants were of the opinion that LFT should be implemented as a package considering all associated factors of tapper shortage. Further, the need of a dissemination process which will demonstrate the effectiveness of the LFT and other measures to tackle the tapper shortage, were emphasised. Accordingly, the measures given in Table 5 were formulated by the participants. 
Table 5. Measures to overcome the tapper shortage along with Low frequency tapping (Rodrigo et al., 2004).

\begin{tabular}{l} 
To upgrade the social status of tappers and their social security; \\
- $\quad$ Provision of uniforms to tappers \\
Provision of adequate recognition using a proper designation to tappers. \\
Awareness programmes on the importance of the tapping profession even at school \\
level. \\
\hline To improve the knowledge and skill of tappers; \\
- $\quad$ Awareness programmes on LFT. \\
To upgrade financial status of tappers; \\
Introduction of attractive incentive payment schemes for additional latex brought by \\
tappers. \\
Maintaining the transparency in latex weighing and payments to tappers. \\
Provision of fringe benefits to tappers (eg. uniforms, pension schemes, meals and \\
health care facilities). \\
Introduction of banking systems and cooperative societies to encourage tappers to \\
adopt proper finance handling systems. \\
Adoption of rainguard technology to increase the number working days of tappers. \\
To reduce the tediousness in tapping operation; \\
Improvement in ground conditions eg. making foot paths and weeding, providing \\
latex transport facilities and additional collecting centres to avoid head carrying of \\
latex. \\
Provision of good quality tapping utensils. \\
Adoption of the techniques on division of labour, e.g. skill tappers are employed \\
only for tapping and sundry workers for other activities in tapping operation such as \\
cup cleaning and latex collection.
\end{tabular}

Participants proposed to launch a national programme giving due consideration to the points mentioned in Table 5 in 40-50 estates. In each estate, an extent of $c a$. 50 ha is initially allocated for this programme and these sites are to be used as both adaptive research sites and models for the demonstration in the national programme to overcome tapper shortage. Plantation companies are prepared to provide partial funding for the programme, if the financial assistance to cover the cost on materials and monitoring is met by another party.

\section{Smallholder sector}

Outcome of the rapid appraisal

Labour use in tapping was generally either hired or family labour and only few smallholdings were found to be tapped with both types of labour. The majority of smallholdings tapped by own family member were falling 


\section{H L Rodrigo}

below 2 hectares, whilst it was vice versa in the case of smallholdings tapped with hired labour (Fig. 2). No smallholdings were found below one hectare and over $20 \%$ were above 5 ha in the hired labour category (Fig.2). Number of smallholders participated in rubber based agricultural societies was greater in the hired labour than in family labour category, particularly in Kalutara and Rathnapura (Table 6). Final form of the farm gate product was more or less same under two types of labour use. The majority of farmers produced smoked sheets (ca. 82\%) whilst the rest, sold their rubber as latex for the centrifuged latex production (Table 6). Most of rubber in smallholdings was below 15 years old (ca. 67\%). However, smallholders in the family labour category had greater number young holdings, i.e. below 10 years, when compared to those in hired labour category (Fig. 3).

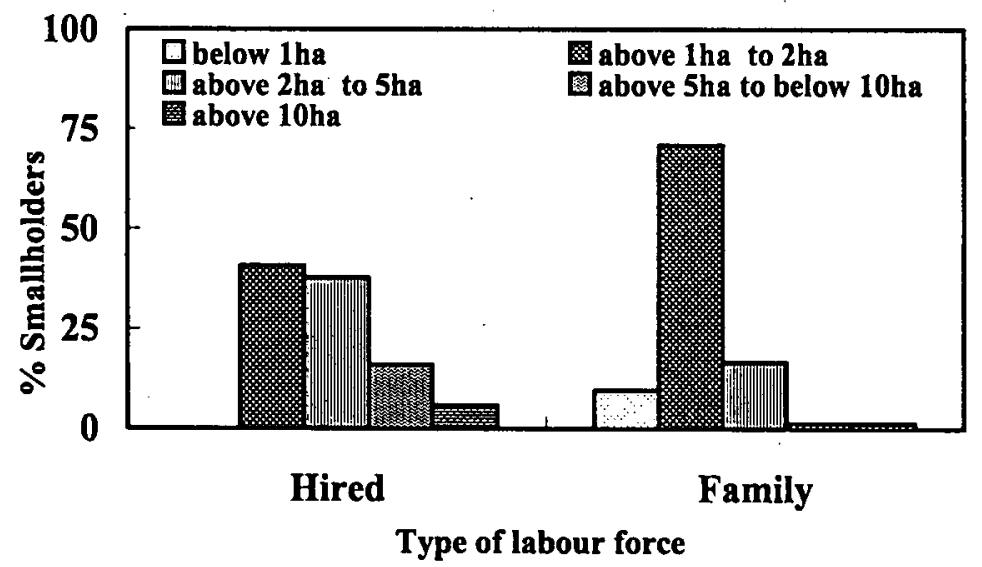

Fig. 2. Holding size of rubber lands in the smallholder sector

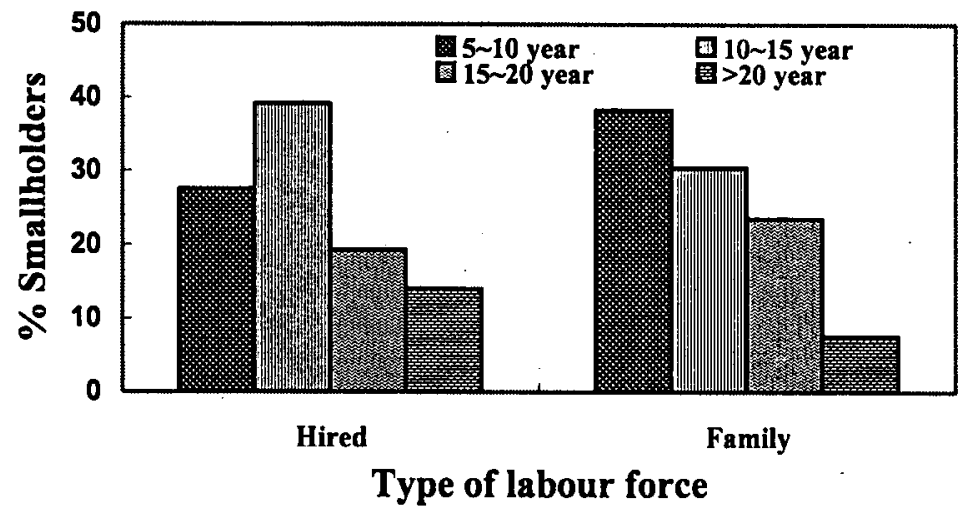

Fig. 3. Age distribution of rubber trees in rubber lands of the smallholder sector 
Table 6. An overview of some agronomic and social parameters in the smallholder conditions in three districts where rubber is mainly grown. Values are given in percentage of farmers except for trees with quality tapping (1.e. \% mean trees) and the intake per tapper $(\mathrm{kg}$ ).

\begin{tabular}{|c|c|c|c|c|c|c|c|}
\hline \multirow[t]{2}{*}{ Parameter } & \multirow[t]{2}{*}{ Level } & \multicolumn{2}{|c|}{ Kalutara } & \multicolumn{2}{|c|}{ Kegalle } & \multicolumn{2}{|c|}{ Rathnapura } \\
\hline & & Hired & Family & Hired & Family & Hired & Family \\
\hline \multirow{2}{*}{ 1. Tapping frequency } & Daily (d/1) & 78.57 & 77.78 & 40.00 & 31.25 & 90.91 & 75.86 \\
\hline & \multirow[t]{3}{*}{ Alternate days $(\mathrm{d} / 2)$} & 21.43 & 22.22 & 60.00 & 68.75 & 9.09 & 24.14 \\
\hline 2. Trees with quality tapping $(\%)$ & & 68.25 & 62.46 & 65.67 & 61.27 & 84.60 & 81.40 \\
\hline 3. Intake per tapper $(\mathrm{kg})$ & & 5.39 & 4.10 & 5.00 & 3.00 & 9.00 & 4.70 \\
\hline \multirow[t]{2}{*}{ 4. Type of final product } & Shects & 71.42 & 72.41 & 73.33 & 26.66 & 88.46 & 11.53 \\
\hline & \multirow[t]{2}{*}{ Latex } & 28.52 & 27.58 & 86.67 & 13.33 & 100 & 0 \\
\hline 5. Social participation & & 50.00 & 18.52 & 25.93 & 31.03 & 53.33 & 33.33 \\
\hline 6. Rainguards & Fixed & 0 & 0 & 50 & 0 & 0 & 0 \\
\hline \multirow[t]{3}{*}{ Reasons for not fixing } & Pest damage & 7.14 & 0 & 0 & 0 & 0 & 0 \\
\hline & Time consuming & 7.14 & 0 & 0 & 0 & 0 & 0 \\
\hline & Brownbast & 85.72 & 100 & 50 & 100 & 100 & 100 \\
\hline 7. Tapping skill & Skilled & 92.86 & 75.86 & 84.62 & 69.23 & 84.00 & 55.17 \\
\hline \multirow[t]{3}{*}{ 8. Ability to find tappers } & Difficult & 80.00 & 92.85 & 37.50 & 46.67 & 80.58 & 93.10 \\
\hline & Not difficult & 20.00 & 7.14 & 43.75 & 53.33 & 9.71 & 6.89 \\
\hline & Indifference & 0 & 0 & 18.75 & 0 & 9.71 & 0 \\
\hline \multirow[t]{2}{*}{ 9. Ability to find sundry labour } & Difficult & 71.43 & 79.31 & 46.15 & 46.67 & 84.62 & 89.66 \\
\hline & Not difficult & 28.57 & 20.69 & 53.85 & 53.33 & 15.38 & 10.34 \\
\hline \multirow[t]{2}{*}{ 10. Fertilizer application } & Irregular & 35.71 & 20.69 & 33.33 & 6.25 & 6.90 & 11.11 \\
\hline & No applied & 64.29 & 79.31 & 66.67 & 93.75 & 93.10 & 88.89 \\
\hline \multirow[t]{4}{*}{ 11. Occupation of the houschold } & No & 8.70 & 6.90 & 40 & 6.67 & 20.00 & 28.00 \\
\hline & Laborious jobs & 4.35 & 79.31 & 13.33 & 73.33 & 12.00 & 68.00 \\
\hline & Low income permanent & 65.22 & 13.79 & 13.33 & 13.33 & 44.00 & 4.00 \\
\hline & High income jobs & 21.74 & 0 & 33.33 & 6.67 & 24.00 & 0 \\
\hline \multirow[t]{4}{*}{ 12. Income } & $<$ Rs.5000 & 7.14 & 56.67 & 13.33 & 53.33 & 11.54 & 84.62 \\
\hline & Rs. $5000-10000$ & 7.14 & 23.33 & 26.67 & 33.33 & 15.38 & 11.54 \\
\hline & Rs. $10000-20000$ & 51.85 & 16.67 & 26.67 & 13.33 & 30.77 & 3.85 \\
\hline & $>$ Rs. 20000 & 33.33 & 3.33 & 33.33 & 0 & 42.30 & 0 \\
\hline
\end{tabular}


Majority of smallholders practised daily tapping $(d / 1)$ with the exception of Kegalle district (Table 6), although the recommended tapping frequency for the clones planted was once in two days $(d / 2)$. Variation of the tapping system with the type of the labour used in tapping was not significant with that $\mathrm{d} / 1$ tapping was practised in $c a$. $64 \%$ and $67 \%$ of the smallholdings tapped with hired and family labour, respectively. Trees with quality tapping fell below $70 \%$ in most of rubber lands, particularly in Kalutara and Kegalle regions. Rainguards on tapping panels have been fixed only in few smallholdings in Kegalle (i.e. only in ca. $8 \%$ of the smallholdings surveyed) due to the fear on Tapping Panel Dryness which results in unyielding trees (Table 6).

Average intake per tapper, i.e. amount of rubber harvested by a tapper per day, was ca. $16 \%$ higher in the smallholdings tapped with hired labour when compared it with those tapped with family labour. Similarly, the availability of skilled tappers and quality of tapping were greater in smallholdings tapped with hired labour than in smallholdings tapped with own family labour (Table 6). Majority of the smallholders were of the view that finding skilled tappers is difficult. Except in the Kegalle region, this was a main issue for over $80 \%$ of smallholdings tapped with own family labour (Table 6). Also, the situation was same in finding sundry workers for other cultural practices (Table 6).

Majority of smallholders have not applied fertilizer for mature rubber. Even where it was done, fertilizer application has been erratic with no proper schedule. However, incident of fertilizer application in smallholdings tapped with hired labour was $70 \%$ greater than that in the smallholdings tapped by family labour (Table 6).

Smallholders possessing the holdings tapped by hired labour appeared to be highly educated with that over $25 \%$ were in the categories above G.C.E. (O.L.). Also, only $8 \%$ were below the grade 8 . In contrast, $\mathrm{ca}$. $50 \%$ of smallholders were falling into the educational categories below grade 8 in holdings tapped with family labour (Fig.4). The majority of smallholders who used hired labour for tapping were involved in high income occupations on permanent basis. Depicting the involvement in tapping themselves, in the smallholdings tapped with family labour, land owners were engaged in low or medium income generating jobs. Similarly, smallholders with rubber tapped with hired labour were in the high income groups whist it was vice versa in the smallholdings tapped with family labour (Table 6). The majority of smallholders were falling in the medium level social category irrespective of the type of labour use. However, in the high level of social category, there were greater number of smallholdings tapped with hired labour than the smallholdings tapped with own family labour. Also, the number of smallholders falling into low level of social stratum was greater in smallholdings tapped with own labour (Fig.5). 
Tapping systems in Sri Lanka

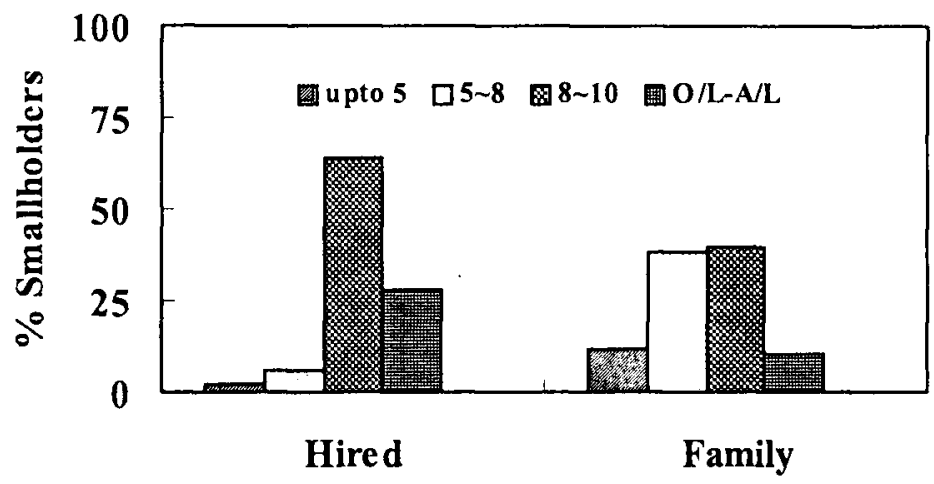

Type of labour force

Fig. 4. Education level of the householders under different types of labour use

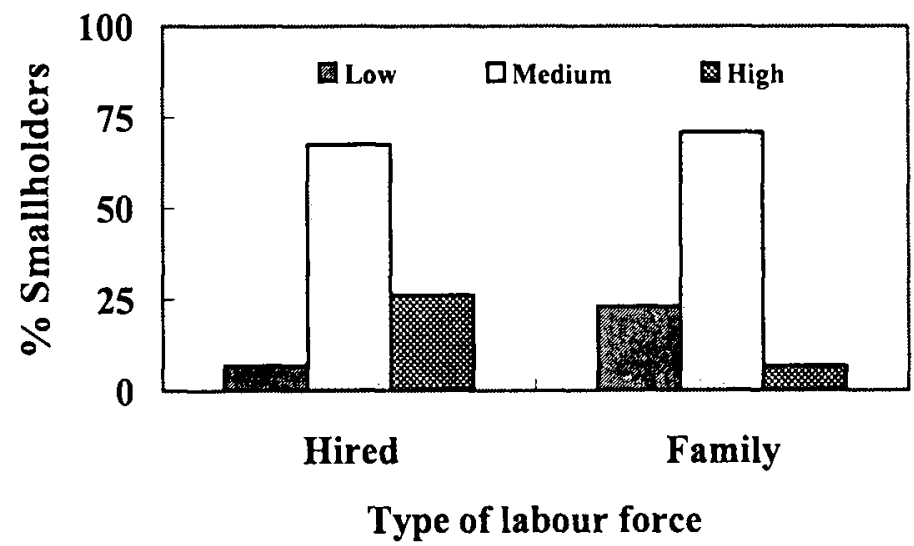

Fig. 5. Social status of smallholders falling into different types of labour use in tapping

Outcome of the workshops

In all regions, participants had no disagreement on the findings of the survey. Not a single participant was aware on LFT. However, a few smallholders had heard about use of stimulants in tapping but had no experience or knowledge in using them. Possibility of using stimulants in combination with LFT was totally unknown.
Although the shortage of tappers was considered as a problem, tapping has been undertaken in every smallholding. Wages given to tappers varied between villages. In some instances, tappers have been paid on sharing crop basis which appeared to be effective to attract tappers. The highest level of payment to tappers appeared as $50 \%$ value of the latex plus scarp collected. In addition to tapping, this 


\section{H L Rodrigo}

included the head carrying of latex and involvement in initial processing (eg. coagulation and preparation sheet).

In order to assess the feasibility of LFT in the smallholder sector, the advantages of LFT were explained with respect to low tapper requirement, high yield per tapper and low cost on tapping to participants. Medium scale growers (eg. owners with over 5ha) showed some interest in LFT. However small scale rubber growers, particularly those tapping is done with own labour wanted to have daily income. If a smallholder is having one or two tapping blocks tapped with hired labour, LFT would not provide daily income to tappers. The possibility of hiring tappers jointly by smallholders (eg. one tapper by three smallholders having one tapping block each) was inquired; however, participants had no confidence in such system and they were of the opinion that if rubber smallholder societies are functioning well, this would be an option.

\section{Discussion}

Tapper productivity of rubber plantations in both estate and smallholder sectors of Sri Lanka appeared to be rather poor when compared to that of neighbouring countries. It could be attributed to the existing levels of land productivity (Anon, 2004) suggesting that agromanagement conditions have to be improved. In perennial crops like rubber, the yield potential of mature trees basically depends on the quality of planting materials used at the beginning and how plants are looked after during the immature phase. Raising the productivity through these factors is a long-term strategy, however, it has been evident that a substantial yield improvement could be achieved within a short period by correct application of tapping techniques. Unskilled tappers have largely been employed in Sri Lankan plantations and that would have been the single most important factor which affects the quality of tapping. According to Nugawela et al. (2000), yields obtained by unskilled tapperes are generally $25 \%$ less than those of skilled tappers. Poor quality tapping reduces not only the instantaneous latex yield but also long-term latex and timber yield potential of rubber trees with irreversible damages to the bark and wood.

\section{Plantation sector}

In the absence of regular tappers (i.e. permanent tappers) in required numbers, substitute tappers who are undoubtedly unskilled, are generally used to minimise the yield loss in untapped (vacant) tapping blocks in estates. More importantly, poor attendance of tappers resulted in large extent of untapped area on each day and it was another factor for low level of land productivity. Even with substitute tappers, it was clearly evident that existence of untapped area had not been totally wiped out with that $c a .12 \%$ of mature rubber extent were untapped. In a situation where number of tappers is 
inadequate, obviously the low yielding areas are first to be left out without tapping, however, it is still a significant share of the total yield of an estate. Had there been no such level of untapped area, the present level of average yield per hectare per year (YPH) would have approached the value $1000 \mathrm{~kg}$. The YPH could be further increased, if unskilled tappers are replaced by skilled tappers.

In the plantation sector, the majority of tappers (i.e. ca. $80 \%$ ), were employed on permanent basis. The rest, i.e. substitute tappers, is considered to be almost unskilled; and even among permanent tappers, a significant share was unskilled explaining why \% unskilled- exceeded the \% substitutetappers. On this basis, the portion of the permanent tappers falling into unskilled category could be estimated as $c a$. $18 \%$. In order to overcome the yield losses in the traditional $d / 2$ tapping system resulting from the existence of vacant tapping blocks and unskilled tappers, the tapper availability should be increased by over $12 \%$ together with a proper programme to convert unskilledto skilled-tappers. Tapper training programmes would be one solution especially for the latter, however there should be a proper incentive scheme to motivate the tappers to continue with their quality tapping. Improved remunerations would play a big role in this regard. Most of the estates in Sri Lanka adopt special payment schemes for tappers to encourage them to harvest for high yields. However, the biggest weakness of these schemes is that there is no any assessment on the quality of tapping. Tappers would therefore try to bring maximum possible yields with no intention to protect the long-term yield potential of rubber trees.

When compared with casual labourers of the estate, tappers could earn little more through the incentive schemes which are based on latex yields harvested, however those incentive schemes may not be attractive or competitive enough to retain good tappers or recruit new ones. Also, the estate managers are concerned with the existing level of expenditure on tapping which is supposed to be $c a$. $40 \%$ of the cost of production of rubber (Nugawela et al., 2000). Therefore, any further increase in the wages of tappers should depend on the amount of latex harvested by them. Low frequency tapping systems facilitate to increase the number of trees allocated to each tapper thereby reducing the tapper requirement. In Sri Lanka, the low frequency tapping system (LFT), i.e. tapping once in three days with $2.5 \%$ ethephon stimulation four times per year (i.e. $1 / 2 \mathrm{~S} d / 3$ $\mathrm{ET} 2.5 \% 4 / \mathrm{y}$ ), has been proven to produce similar yields given by the traditional alternate day $(\mathrm{d} / 2)$ frequency tapping (Nugawela et al., 2000). Obviously, with given three tapping blocks to each tapper, it reduces the requirement of tappers by one third over the traditional $d / 2$ system with that the tapper shortage of most of estates can be solved only with skilled tappers. If LFT, i.e. $\mathrm{d} / 3$ frequency with ethephon 


\section{H L Rodrigo}

stimulation, were practised on either fully or partly, the tapper shortage of almost all estates would have been overcome. Out of 55 estates used for the present study, the tapper shortage of 42 estates $(76 \%)$ could be fully addressed by the LFT only with the permanent tappers leaving only 13 estates which may require some substitute tappers. More importantly, the tapping cost is reduced by $c a$. $20 \%$ due to increase in tapper productivity resulted by the increase in latex yield per tree per tapping in LFT (Nugawela et al., 2000). Increased tapper productivity in the $d / 3$ system leads to increase the daily income of tappers thereby motivating them to be in tapping profession.

Annual bark consumption rate of the $d / 3$ is less than that of traditional $\mathrm{d} / 2$ system of tapping due to less number of tapping days per year and as a result, the economic lifespan, i.e. tapping cycle, could be increased by $c a$. 6 years (Nugawela et al., 2000). This will increase the extent of mature rubber fields (i.e. revenue area) of an estate increasing the overall profitability. Managing companies of rubber estates had little or no interest in replanting uprooted rubber during the recent past when the rubber prices were very low and now plan to implement huge replanting programmes with the increase in rubber price. In this context, the LFT will help to continue the tapping in existing mature clearings thereby delaying uprooting and maintaining the mature/immature ratio of the rubber crop at an economical level.

Not like in casual work, more women were engaged in tapping than men. Tapping requires a skill and perhaps it would be easier for women to obtain this skill. These factors could be taken into consideration in tapper training programmes. If it is required to retain females in tapping, sufficient support should be given to reduce the tediousness in the tapping process, e.g. facilities to collect latex in order to prevent head carrying. This is particularly important in LFT systems of which daily latex intake of tappers is greater than that of the traditional $\mathrm{d} / 2$ tapping.

A similar pattem of age distribution was shown in both tappers and casual workers. Although total labour force in the country between 2030 and $30-40$ is more or less same (Anon., 2002), only a few tappers/casual workers were in the young age categories, i.e. below $30 \mathrm{yrs}$, showing the unwillingness of the young generation for this type of jobs as proven in the workshop. Tapping is also considered to be a labour job for the people with no proper educational background. Particularly in Sri Lankan social context, tapping has lower level of social recognition compared to the most of other jobs for the same category of people. Therefore, young people with no proper educational background may prefer to join other jobs falling into the little higher level of the social ladder in the first instance, e.g. factory workers. It may also be necessary to take steps to 
upgrade the social status of tapping profession as mentioned in the Table 5 to overcome tapper shoratge. For instance, changing the designation, mindset at school level and proper uniforms could be considered in this regard. Also, necessary steps should be taken to establish the income stability of tappers.

\section{Smallholder sector}

Unlike in the plantation sector, information on productivity in rubber smallholdings is not recorded properly, and as a result accurate data cannot be obtained by the rapid appraisals. However, the present study revealed very useful information which has not been recorded before. Rubber in smallholdings was generally tapped by either family or hired labour and the involvement of both types in one holding was found only in a few cases. The majority of farmers sold rubber as either smoked sheets or as latex with the former having highest share ( $c a .82 \%$ ).

The study revealed that trees with good quality tapping were below $70 \%$ in the smallholdings. However, it was higher in Rathnapura region when compared with other regions and also in situations where tapping is done with hired labour. Moreover, the skill of tappers was greater in hired labour than in family labour conditions. In fact, when hiring tappers, landowners would be selective on skilled tappers and emphasise on quality tapping resulting in high yields as indicated by higher intake per tapper.
Educational background of the smallholders showed a close association with their occupational and income levels. Smallholders whose rubber was tapped with hired labour had high level of education and the high income generating occupations. With poor educational qualifications, the opportunity cost for own labour was low resulting in that tapping is done by the land owners. However, the majority of smallholders were in the medium level social category. Being a remunerative crop, rubber would have contributed to place smallholders in a socially acceptable level.

The size of the holdings would also have been a deciding factor for the type of labour used in tapping. Although the majority of smallholdings were below 2 hectares, there were a significant number of lands above the 2ha. level tapped by hired labour when compared to the land size of the holdings tapped with family labour. Also, no lands below 1 ha. were found in the category of hired labour. Rubber in most of smallholdings were below 15 years old; however smallholders who used their own labour for tapping had more young rubber, i.e. ca. $38 \%$ below 10 years. This suggests that farmers in this category were able to afford planting rubber due to their low cost of production during the latter part of last decade when rubber prices were very low.

Low Frequency Tapping has not been practised in any smallholdings. Instead, rubber has been tapped on daily 
basis in the majority of smallholdings irrespective to the type of labour use, although the highest frequency allowed is alternate day tapping as per the recommendation of the RRISL. Although daily tapping provides daily yields, it is considered to be a stress to the rubber tree affecting the long term yield potential of it. Therefore, no high yields could be obtained through daily tapping on long run (eg. per year basis) when compared with alternate day tapping or LFT. Also, daily tapping may lead to permanent disability of some rubber trees to produce latex, i.e. Tapping Panel Dryness (TPD) (Krishnakumar et al., 2003). Fertilizer application has also not been done properly, reflecting poor agromanagement practises. No information was available on the quality of planting material used at the beginning, however, poor upkeep and intensified tapping explain the low daily intake of tappers.

Due to poor intakes in the present system of daily tapping, tapping cost of each rubber kilogram produced is higher than that has been recorded for alternate day tapping or LFT. Some smallholders had a psychological satisfaction of getting daily income through daily tapping whist some were in the opinion that daily tapping is required to retain tappers with them. Some farmers were aware of the repercussions of daily tapping however they justified it as a solution for the problem of no tapping resulted by rain interference. Fixing rainguards was not a common practise, however if smallholders apply rainguards with the practice of daily tapping, the situation may be worse with more TPD affected trees. Therefore, the promotion of use of rainguards should be done along with correct tapping frequency.

Three different organisations, namely Rubber Development Department, Advisory Department of the RRISL and Thurusaviya programme are working on rubber extension in the country. Also, significant number of farmers has been members of the rubber based agricultural societies. However, knowledge transfer on the latest technologies to farmers appeared to be not very effective. A classic example is ignorance of farmers about LFT. Also, use of rainguard is not common among smallholders. Since benefits of LFT are not known to the farmers, awareness programmes should be conducted to educate them on this system. Also, field demonstration plots established on farmers' lands are essential to build up their confidence on LFT. With lack of interactive extension activities, social organisations on rubber too were not working properly. Sharing tappers by few smallholders is necessary in LFT for the farmers with small piece of land and this could be effectively handled through farmers' organisations. Therefore, in any popularisation programme of LFT, such cluster working systems should be encouraged among farmers. Since the tapping cost under hired labour conditions is greater than that of family labour, the smallholdings tapped with hired labour 
Tapping systems in Sri Lanka

can be set as the initial target group for popularisation of LFT.

\section{Overview}

Adoption of LFT was rather poor in the plantation sectors and it was non existent in the smallholder sector. Should the LFT be implemented properly, the present problem of tapper shortage in Sri Lankan estates can be solved. Tapping cost can also be reduced with LFT. This system is of particular importance to growers who depend on hired labour for tapping.

Most of the managers in the plantation sector did not know the protocol of LFT and its advantages. Smallholders were totally unaware of the LFT. This suggests that publicity given so far on LFT has not been sufficient. Therefore, extension programmes have to be strengthened with effective tools to disseminate the technology (e.g. awareness programmes and demonstration plots) in order to overcome tapper shortage whilst uplifting the productivity and profitability of rubber. In the estate sector, a division ( $c a$. 50ha) each from 40-50 estates could initially be used for the setting up the adaptive research plots and models for demonstration purpose of the LFT. Similarly, for the smallholder sector too, few model cluster systems should be set up in each rubber growing regions to demonstrate the effectiveness and advantages of LFT.

Rubber growers were unaware of the recommendations on some other important agronomic practices suggesting an overall weakness in technology transfer. For instance, the present study revealed that d/3 tapping without stimulation is still being adopted during the first year in tapping of rubber trees though it is not recommended. Rainguards were fixed only in a few smallholdings and also, clones recommended for $\mathrm{d} / 3$ tapping without stimulation have not been planted in the plantation sector to a greater extent. At the moment, there is no proper system to assess the accountability of extension activities, particularly in the smallholder sector. The strengthening process of extension activities, therefore, is essential.

A large number of unskilled tappers are in the rubber industry, particularly in the plantation sector and in smallholdings tapped by family labour. In order to improve the tapping skills of those, training programmes should be conducted. Although tapping is considered to be a less dignified job in the society, it is not an issue when family labour is used for tapping as they are the owners of the land. Therefore with proper training, those family tappers could be retained in the industry and the productivity of such smallholdings increased. In the plantation sector, tapper-training programmes should be accompanied with measures on upgrading the social and financial status of tappers. Also, measures to reduce the tediousness of tapping need to be implemented particularly when skilled female tappers are employed. 
V H L Rodrigo

\section{Acknowledgement}

This study was funded by the

Council for Agricultural Research Policy of Sri Lanka. Research activities were conducted with the valuable assistance of the staff of the Plant Science Department of Rubber Research Institute of Sri Lanka and Rubber Development Department. In particular, technical support given by Ms R D Vidanapathirana, Ms G P Wijesinghe, Mr P K W Karunathilake and $\mathrm{Mr} \mathrm{P} D$ Pathirana is highly appreciated.

\section{References}

Anon (1994). Advisory circular - Tapping 1994/05. Rubber Research Institute of Sri Lanka.

Anon (2002). Quarterly report of the Sri Lanka labour force survey. Department of Census \& Statistics of Sri Lanka.

Anon (2004). Rubber Statistical Bulletin 58

(6). International Rubber Study Group, Wembley, UK.

Karunaichamy, K, Vijayakumar, $\mathrm{K}$ R, Thomas, K U, Rajagopal, R and Kumar, D A (2001). Response of rubber trees (Hevea brasiliensis Muell. Arg., clone RRII 105) to low frequency tapping (LFT) systems. Indian Journal of Natural Rubber Research 14(2), 79-87.

Krishnakumar, R, Thomas, M, Sobhana, $\mathrm{P}$ and Jacob, J (2003). Tapping panel dryness syndrome: a review. International Workshop on Exploitation Technology; IRRDB, 15-18 December 2003 Kottayam, India.

Nugawela, A, Peries, M R C, Wijesekera, S and Samarasekera, R K (2000). Evaluation of $d / 3$ tapping with stimulation to alleviate problems related to $\mathrm{d} / 2$ tapping of Hevea. Journal of the Rubber Research Institute of Sri Lanka 83, 49-61.

Rodrigo, V H L, Wickramarathna, N A A D and Vidanapathirana, R D (2004). Productivity and tapper shortage in rubber plantations: how low frequency tapping can address the shortage of tappers in rubber plantations of Sri Lanka. Proceedings of the first symposium on Plantation Crop Research, July 8-9 2004, BMICH, Colombo. pp. 32-42.

Vijayakumar, $\mathrm{K} \dot{\mathrm{R}}$, Thomas, $\mathrm{K} \mathrm{U}$ and Rajagopal, R (2000). Tapping. In: Natural Rubber - Agro-management and Crop processing, pp. 239-249 (Eds. P.J. George and C.K. Jacob) Rubber Research Institute of India.

Vijayakumar, K R, Mohd. Akbar Md. Said, Pichit Sopchoke, Do Kim Thanh, Rodrigo, V H L and Mak Sopheaveasna (2005). Recommendation and practices in exploitation technology of Hevea trees in different countries of Asia. IRRDB Workshop on Transfer of Technology, 4-6 April 2005, Kuala Lumpur.

Wei Xiaodi, Xiao Xianzhou and Chen Qiubo (2005). Rubber exploitation technology in China. Chinese Academy of Tropical Agricultural Sciences, Danzhou, Hainan Province, PRC. IRRDB Workshop on Transfer of Technology, 4-6 April 2005, Kuala Lumpur.

Address for correspondence: $\mathrm{Dr} \mathrm{V} \mathrm{H} \mathrm{L}$ Rodrigo, Head, Biochemistry and Plant Physiology Dept., Rubber Research Institute of Sri Lanka, Dartonfield, Agalawatta, Sri Lanka.

E-mail: laksh@sitnet.lk 